\title{
CONTABILIDADE TRIBUTÁRIA: OS EFEITOS DA DESONERAÇÃO DE CONTRIBUIÇÕES PREVIDENCIÁRIAS SOBRE AS TARIFAS DE TRANSPORTE INTERMUNICIPAL DE PASSAGEIROS NO RIO GRANDE DO SUL
}

TAX ACCOUNTING: THE EFFECTS OF SOCIAL SECURITY CONTRIBUTIONS OF RATES ON INTERMUNICIPAL PASSENGER TRANSPORT IN RIO GRANDE DO SUL CONTABILIDADE TRIBUTARIA: LOS EFECTOS DE LO ABARATAMIENTO DE
LA CONTRIBUCIÓN A LA SEGURIDAD SOCIAL SOBRE LAS TARIFAS DE
TRANSPORTE INTERMUNICIPAL DE PASAJEROS EN RIO GRANDE DO SUL

Victor Scur Barth

Graduado em Ciências Contábeis pela Universidade Federal do Rio Grande do Sul (UFRGS), Brasil victorsbarth@gmail.com

Angela Rozane Leal de Souza

Doutora em Agronegócios pela UFGRS; Professora Adjunta da UFRGS angela.rsl@gmail.com

\section{Letíca de Oliveira}

Doutora em Agronegócios pela UFRGS; Professora Adjunta da UFRGS leoliveira13@gmail.com
Contextus

ISSNe 2178-9258

Organização: Comitê Científico Interinstitucional Editor Científico: Carlos Adriano Santos Gomes Avaliação: Double Blind Review pelo SEER/OJS Revisão: Gramatical, normativa e de formatação Recebido em 11/09/2015 Aceito em 17/08/2016 $2^{a}$ versão aceita em 10/10/2016

\section{RESUMO}

A partir de 2011, por meio do "Plano Brasil Maior", o Brasil adotou medidas, dentre estas a criação da contribuição previdenciária sobre a receita bruta, em substituição ao INSS patronal sobre a folha de pagamentos, incluindo o transporte público nessa desoneração a partir de 2013. O objetivo foi analisar a influência da desoneração tributária no cálculo das tarifas de transportes intermunicipais, avaliando questões relativas ao equilíbrio econômico dos prestadores de serviços públicos, nos anos de 2013 e 2014. Os dados foram coletados dos relatórios disponibilizados no website da AGERGS, elaborados para tais anos. Os principais resultados da pesquisa apontam que houve redução no valor do coeficiente tarifário de todos os sistemas de transporte regulados pela agência, dando destaque para o sistema da aglomeração urbana do sul. Apurou-se, neste estudo, que os impactos da desoneração nos coeficientes tarifários giram em torno de $2,5 \%$ a $4,5 \%$. Essa modificação afetou a estrutura das empresas, influenciando no ponto de equilíbrio contábil e no giro de ativos.

Palavras-chave: Tributos. Contribuição previdenciária. Transporte público.

\section{ABSTRACT}

From 2011 on, when the "Plano Brasil Maior" was launched, Brazil has adopted measures, among them the creation of social security contributions on gross revenues, replacing INSS employer on the payroll, including the public transport in this exoneration from 2013 on. The objective was to analyze the influence of tax exemption in the calculation of intercity transportation fares, evaluating issues relating to the economic balance of public service 
providers, in the years 2013 and 2014. Data were collected from reports available on the website of AGERGS, prepared for such years. The main results of the survey indicate that there was a reduction in the value of tariff coefficient of all transport systems regulated by the agency, highlighting the southern urban agglomeration system. It was found in this study that the impacts of exoneration in the tariff coefficients are around $2.5 \%$ to $4.5 \%$. This change affected the structure of the companies, influencing the accounting breakeven and asset turnover.

Keywords: Taxes. Social security contribution. Public transportation.

\section{RESUMEN}

Desde 2011, a través del "Pan Brasil Mayor", Brasil adoptó medidas, entre ellas la creación de la contribución de la seguridad social sobre los ingresos brutos, en sustitución al INSS patronal en la nómina de pago, incluyendo el transporte público en esa desgravación desde 2013. El objetivo fue analizar la influencia de la desgravación tributaria en el cálculo de las tarifas de transporte intermunicipales, con la evaluación de las cuestiones relacionadas con el equilibrio económico de los proveedores de servicios públicos, en los años 2013 y 2014. Los datos fueron obtenidos de los informes disponibles en el website de AGERGS y preparados para dichos años. Los principales resultados de la investigación muestran que hubo una reducción en el valor del coeficiente de tarifas de todos los sistemas de transporte regulados por la agencia, destacando el sistema de aglomeración urbana del sur. Este cambio afectó la estructura de las empresas, influyendo en el punto de equilibrio contable y en la rotación de activos.

Palabras claves: Impuestos. Contribución a la Seguridad Social. Transporte público.

\section{INTRODUÇÃ̃o}

\section{O Sistema Tributário Legal}

brasileiro é representado pelo conjunto de normas que definem e delimitam o processo de arrecadação de recursos que financiarão os gastos governamentais, sendo chamados de tributos. Nesse cenário, existem as chamadas desonerações tributárias ou, ainda, gastos tributários que ocorrem na existência de anistias, isenções, presunções creditícias, redução de alíquotas, deduções, abatimentos e adiamentos de obrigações tributárias (BRASIL, 2014b). Assim sendo, a contabilidade tributária é utilizada para designar o conjunto de ações e procedimentos visando apurar e conciliar os tributos de uma entidade (ELDENBURG; WOLCOTT, 2007).

Desse modo, o Demonstrativo dos Gastos Governamentais Indiretos de Natureza Tributária (BRASIL, 2014b, p. 10) especifica o que são gastos tributários.

Gastos tributários são gastos indiretos do governo realizados por intermédio do sistema tributário visando atender objetivos econômicos e sociais.

São explicitados na norma que referencia o tributo, constituindo-se uma exceção ao sistema tributário de referência, reduzindo a arrecadação potencial e, consequentemente, aumentando a disponibilidade econômica do contribuinte.

Têm caráter compensatório, quando o governo não atende adequadamente a população dos serviços de sua responsabilidade, ou têm caráter incentivador, quando o governo tem a intenção de desenvolver determinado setor ou região. 
Esses gastos podem servir para diversos fins, como a simplificação e/ou redução dos custos da administração, a promoção da equidade, a correção de desvios, o incentivo de determinado setor da economia, entre outros. Algumas dessas alternativas se constituem de ações políticas de governo que têm como objetivo a promoção do desenvolvimento econômico ou social que são realizados por meio do sistema tributário e não pelo orçamento governamental.

Nessa conjuntura, pode-se citar a desoneração da folha de pagamento de alguns setores como parte da política industrial, tecnológica e de comércio exterior que se iniciou com a Medida Provisória $\mathrm{n}^{\mathrm{o}}$ 540/2011, a qual foi convertida na Lei Federal $\mathrm{n}^{\circ}$ 12.546, de 14 de dezembro de 2011 e, posteriormente, editada e ampliada por outras Leis Federais. A referida Lei determinou que a contribuição previdenciária patronal básica de $20 \%$, calculada sobre o total da folha de pagamento de empregados, fosse substituída pela aplicação das alíquotas de $1 \%$ ou $2 \%$, conforme o caso, sobre o valor da receita bruta, excluídas as vendas canceladas e os descontos incondicionais concedidos.

Portanto, as empresas mencionadas no texto legal devem obrigatoriamente recolher a contribuição previdenciária sobre a receita bruta e não mais adotar o antigo método. Tal alteração afeta a estrutura financeira da empresa, impactando seu resultado financeiro e a prestação dos serviços ou sua produção de acordo com o setor em que está inserida, como, por exemplo, o transporte público coletivo.

A Lei Federal n. ${ }^{\circ}$ 12.587, de 03 de janeiro de 2012, define o transporte público coletivo como o serviço público de transporte de passageiros acessível a toda a população mediante pagamento individualizado, com itinerários e preços fixados pelo poder público. Os preços levam em conta os custos operacionais, as despesas administrativas e de pessoal e os impostos, variando de acordo com o tipo de transporte, o percurso e a quantidade de passageiros. Assim, compete ao órgão executivo a delimitação dos parâmetros utilizados no cálculo da tarifa, bem como sua revisão e reajuste, para então determinar o valor da remuneração pela prestação do serviço e da tarifa pública a ser cobrada do usuário (BRASIL, 2012a).

Para tanto, este estudo tem a seguinte problemática de pesquisa: quais os impactos econômicos e contábeis da desoneração tributária das contribuições previdenciárias sobre as tarifas de transporte intermunicipal rodoviário de passageiros do Rio Grande do Sul, regulados pela Agência Estadual de Regulação dos Serviços Públicos 
Delegados do Rio Grande do Sul (AGERGS) nos anos 2013 e 2014?

Frente a esta problemática, o objetivo deste estudo é analisar a influência da desoneração tributária no cálculo das tarifas de transportes intermunicipais, avaliando questões relativas ao equilíbrio econômico dos prestadores de serviços públicos nos anos 2013 e 2014.

Com base no objetivo proposto, o presente trabalho está estruturado em seis partes além desta Introdução. O setor de transportes e a Agência Estadual de Regulação dos Serviços Públicos Delegados do Rio Grande do Sul (AGERGS) são caracterizados na segunda parte. Na terceira parte, são apresentadas as tarifas, os custos e tributos no transporte intermunicipal de passageiros, destacandose a desoneração da folha de pagamento sobre as tarifas de transporte interestadual de passageiros, os encargos sobre a folha de pagamento no cálculo das tarifas e as influências no tratamento contábil e giro do ativo das prestadoras de serviços. Uma revisão de literatura sobre o objeto de estudo representa a quarta parte do trabalho. Na sequência, têm-se os procedimentos metodológicos e, na sexta parte, a análise e discussão dos resultados, dividindo-se em resultados dos cálculos tarifários, desconsiderando e considerando os efeitos da desoneração, uma análise comparativa dos efeitos da desoneração sobre os custos e a estimativa dos efeitos contábeis e financeiros. Por fim, tem-se a última parte apresentando as considerações finais $\mathrm{e}$ as referências utilizadas no trabalho.

\section{O SETOR DE TRANSPORTES E A} AGÊNCIA ESTADUAL DE REGULAÇÃO DOS SERVIÇOS PÚBLICOS DELEGADOS DO RIO GRANDE DO SUL (AGERGS)

De acordo com Sousa (2004, p. 17), “o transporte coletivo de longa distância, por ônibus (TCLD), é definido como sendo o transporte intermunicipal, interestadual e internacional de passageiros por ônibus". A Agência Nacional de Transportes Terrestres (ANTT) é o órgão federal competente pela outorga e fiscalização das permissões e autorizações dos serviços de transporte rodoviário interestadual e internacional de passageiros. Quanto ao transporte intermunicipal de passageiros, o controle é feito pelos estados individualmente, sendo regulado, no Rio Grande do Sul, pelo Departamento Autônomo de Estradas e Rodagem (DAER-RS), pela Fundação Estadual de Planejamento Metropolitano e Regional (METROPLAN) e pela Agência Estadual de Regulação dos Serviços Públicos Delegados do Rio Grande do Sul 
(AGERGS) (RIO GRANDE DO SUL, 1998a, 1998b; BRASIL, 2001).

A AGERGS é uma autarquia criada pela Lei $\mathrm{N}^{\mathrm{o}} 10.931$, de 09 de janeiro de 1997, dotada de autonomia financeira, funcional e administrativa, com sede na Capital do Estado. A Agência desenvolve suas atividades, atuando nas áreas de saneamento, energia elétrica, irrigação, transportes intermunicipais de passageiros e estações rodoviárias.

Dentre seus objetivos, cabe à instituição assegurar a prestação adequada dos serviços, modicidade das tarifas aplicadas, garantindo a harmonia dos interesses dos usuários e dos prestadores dos serviços, além de zelar pelo equilíbrio econômico dos serviços públicos delegados. Cabe ainda ressaltar que compete à agência, em seu artigo $4^{\circ}$, inciso V da referida Lei, "fixar, reajustar, revisar, homologar ou encaminhar, ao ente delegante, tarifas, seus valores e estruturas" (RIO GRANDE DO SUL, 1997).

Quanto ao transporte intermunicipal de passageiros, objeto de regulação da AGERGS, o controle é dividido da seguinte forma:

a) Transporte Intermunicipal de Longo Curso: cabe ao DAER e à AGERGS, quando a viagem não ocorre entre municípios que pertencem a uma mesma região metropolitana ou aglomeração urbana (DAER, 2010). Ex.: Porto Alegre/Caxias do Sul; Passo Fundo/Santa Maria, etc.;

b) Transporte Intermunicipal Metropolitano: cabe à METROPLAN e à AGERGS, quando a viagem ocorre entre municípios pertencentes a uma mesma Região Metropolitana ou Aglomeração Urbana (RIO GRANDE DO SUL, 1998b). Ex.: Porto Alegre/Canoas; Caxias do Sul/São Marcos; Pelotas/Capão do Leão, etc.

A Constituição Brasileira, em seu artigo $25, \S 3 .^{\circ}$ do capítulo III, apresenta, em linhas gerais, o que compreende uma região metropolitana e aglomeração urbana:

Os Estados da Federação poderão, mediante Lei complementar, instituir regiões metropolitanas, aglomerações urbanas e microrregiões, constituídas por agrupamentos de municípios limítrofes, visando integrar a organização, o planejamento e a execução de funções públicas de interesse comum. (BRASIL, 1988).

No Estado do Rio Grande do Sul, existe a: (a) Região Metropolitana de Porto Alegre (RMPA) via Lei Complementar Federal $\mathrm{N}^{\mathrm{o}}$ 14, de 08 de junho de 1973, Art. 1, § 3; (b) Região Metropolitana da Serra Gaúcha (RMSG) via Lei complementar estadual $\mathrm{N}^{\circ} 14.293$, de 29 de agosto de 2013; (c) Aglomeração Urbana 
do Litoral Norte (AULINOR) via Lei complementar estadual $\mathrm{N}^{\circ} 12.100$, de 27 de maio de 2004 e; (d) Aglomeração Urbana do Sul (AUSUL) com a Lei complementar estadual $\mathrm{N}^{\circ} 11.876$, de 26 de dezembro de 2002 (RIO GRANDE DO SUL, 2002; 2004, 2013).

Para o entendimento das divisões do transporte intermunicipal de passageiros e aglomerações, é realizado um cálculo tarifário distinto para a fixação da tarifa das linhas de transporte intermunicipal metropolitano de cada região. Também é realizado o cálculo tarifário referente ao transporte intermunicipal de Longo Curso (LC). Cabe salientar que existem diversas empresas de transporte operando em cada uma das aglomerações, porém algumas também operam em mais de uma e no longo curso.

\section{TARIFAS, CUSTOS E TRIBUTOS NO TRANSPORTE \\ INTERMUNICIPAL DE PASSAGEIROS}

Todo sistema de transporte consome recursos para sua operação; assim seu valor está necessariamente atrelado à tarifa, pois integra o funcionamento de toda a parte operacional e administrativa do sistema. Para se integrar esses custos e se obter o custo por quilômetro, a planilha de cálculo tarifário se utiliza de parâmetros de consumo que são medidas de consumo dos custos fixos e variáveis. Por exemplo, na rodagem, o parâmetro é calculado de acordo com a vida útil do pneu, expressa em quilômetros, acrescida da sobrevida obtida por meio de recapagens. $\mathrm{O}$ combustível é calculado de acordo com o consumo anual da frota, dividido pela quilometragem anual percorrida. Para se obter um custo unitário por quilômetro, esse parâmetro de consumo é multiplicado pelo valor unitário do bem consumido que, por exemplo, para o combustível, pode se considerar o preço do litro do combustível em notas fiscais recentes de compra pela empresa ou, ainda, consultar a relação de preços da Agência Nacional do Petróleo (ANP) (AGERGS, 2014).

Além desses itens, a planilha tarifária se utiliza de diversos índices, e uma das variáveis mais importantes para o cálculo da tarifa é o Índice de Aproveitamento Econômico ou Índice de Aproveitamento Padrão (IAP), obtido pela divisão entre o parâmetro da Receita Auferida (REA) e o parâmetro da Receita Teórica (RET). A receita auferida (REA) representa o produto das tarifas efetivas ou pagas pelos usuários da modalidade comum, excluindo-se outras modalidades de serviço (direta, semidireta, seletiva e executiva) pelo tipo de passageiro pagante (estudante, adulto comum, desconto para idosos etc.). Já a Receita Teórica (RET) é o produto do número de viagens por linha 
pela tarifa máxima da linha e pela lotação dos veículos que operam naquela linha. Portanto, o IAP garante a divisão dos custos totais do sistema de transporte entre os passageiros pagantes.

Outro indicador importante é o Percurso Médio Anual (PMA) que corresponde à quilometragem média anual percorrida por ônibus integrante da frota efetiva das operadoras. A quilometragem total percorrida pelo sistema é obtida pelo número de viagens realizadas, multiplicado pela extensão das linhas cadastradas junto à METROPLAN, observando-se o número de dias úteis, sábados, domingos e feriados. Por fim, esse valor é dividido pela frota efetiva das operadoras para se obter o PMA. Sua função é converter em quilômetros todos os custos unitários cujas fórmulas não expressem diretamente essa relação, como, por exemplo, despesas administrativas e com pessoal, depreciação, etc. Assim, a determinação do Coeficiente Tarifário (COET) é o resultado de todo o trabalho e estudo realizado, pois representa o custo total de um veículo por quilômetro e por passageiro. Obtém-se este valor dividindo-se o custo por quilômetro rodado do veículo padrão pelo produto do IAP e a lotação total ofertada em cada linha. Multiplicando-se o COET pela extensão $(\mathrm{Km})$ de cada linha, obtém-se a tarifa da modalidade comum, objeto de regulação direta da agência.

\subsection{Desoneração da folha de pagamento sobre as tarifas de transporte interestadual de passageiros}

A alteração da legislação tributária incidente sobre a folha de pagamento (desoneração da folha) foi realizada por meio da Medida Provisória $\mathrm{n}^{\mathrm{o}}$ 540, de 02 de agosto de 2011, posteriormente convertida na Lei $\mathrm{n}^{\circ} 12.546$, de 14 de dezembro de 2011, e ampliada por alterações posteriores, como a Lei 12.715, de 17 de setembro de 2012 e a Lei 13.043, de 13 de novembro de 2014 (BRASIL, 2012b, 2014a).

Esta medida consiste na substituição obrigatória da base de incidência da contribuição previdenciária patronal sobre a folha de pagamento com a aplicação da alíquota de $20 \%$, baseada nos incisos I e III do art. 22 da Lei ${ }^{\circ} 8.212$, de 24 de julho de 1991, por uma incidência sobre a receita bruta para empresas de determinados ramos da atividade econômica (BRASIL, 2011). Com a mudança de critério da incidência, em termos práticos, houve a criação de um novo tributo: a Contribuição Previdenciária sobre a Receita Bruta (CPRB), que consiste na aplicação de uma alíquota de $1 \%$ ou $2 \%$, a depender da atividade, do setor econômico (Classificação Nacional de Atividades Econômicas - CNAE) e do produto fabricado (Nomenclatura Comum 
do MERCOSUL - NCM) sobre a receita bruta mensal.

Empresas que produzirem diferentes tipos de produtos ou prestarem diferentes tipos de serviços daqueles mencionados na Lei devem continuar apurando a contribuição previdenciária patronal, com base na folha de salários, e devem realizar o recolhimento proporcionalmente ao montante de sua receita total (BRASIL, 2011).
A Figura 1 ilustra a composição da contribuição previdenciária sobre a perspectiva da tributação normal e sobre a desoneração da folha, considerando a cota patronal (alíquota de 20\%) e a do segurado (alíquotas de 8, 9 ou 11\%), o Risco de Acidente do Trabalho (RAT - alíquotas de 1 a 3\%) e a Contribuição Previdenciária sobre a Receita Bruta (CPRB - alíquotas de 1 ou 2\%), além da renúncia fiscal (BRASIL, 1991, 2011).

Figura 1 - Exemplo ilustrativo da composição da contribuição previdenciária

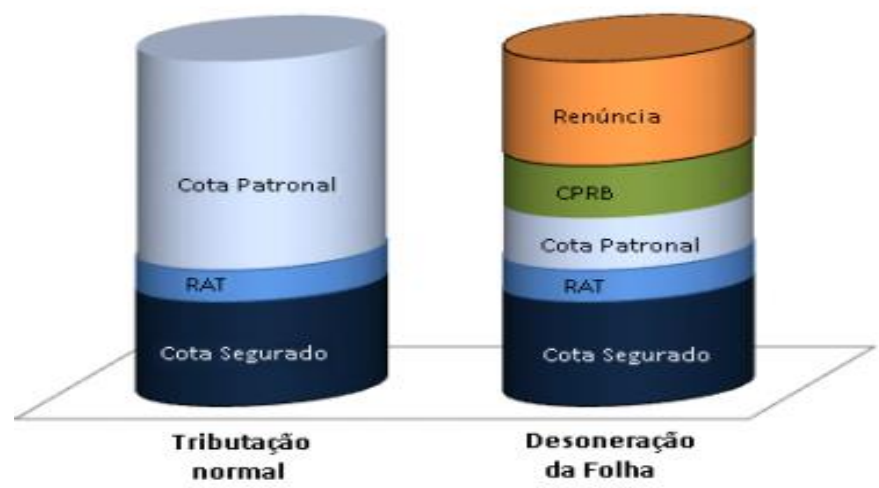

Fonte: Secretaria da Receita Federal do Brasil (BRASIL, 2014c, p. 3).

A Lei $\mathrm{N}^{\mathrm{o}}$ 12.715/2012 ampliou a abrangência de setores contemplados com a desoneração na Lei $N^{\circ} 12.546 / 2011$, incluindo as empresas de transporte intermunicipal de passageiros, e produziu efeitos de 01/01/13 até 31/12/2014 para a concessão do benefício. Todavia, a Lei $\mathrm{N}^{\circ}$ 13.043/2014 tornou definitiva a desoneração dos setores contemplados (BRASIL, 2012b, 2014a).

A Lei $\mathrm{N}^{\mathrm{o}} 12.546 / 2011$, conforme seu artigo sétimo e inciso $3^{\circ}$, apresenta o seguinte:
Art. $7^{\mathbf{0}}$ Contribuirão sobre o valor da receita bruta, excluídas as vendas canceladas e os descontos incondicionais concedidos, em substituição às contribuições previstas nos incisos I e III do caput do art. 22 da Lei no 8.212, de 24 de julho de 1991, à alíquota de $2 \%$ (dois por cento).

[...] III - as empresas de transporte rodoviário coletivo de passageiros, com itinerário fixo, municipal, intermunicipal em região metropolitana, intermunicipal, interestadual e internacional enquadradas nas classes 4921-3 e 4922-1 da CNAE 2.0 (BRASIL, 2011, 2012b, 2014a).

\subsection{Encargos sobre a folha de pagamento no cálculo das tarifas de}




\section{transporte intermunicipal de passageiros}

A folha de pagamento é composta por todas as despesas com mão de obra, considerando o pessoal operacional, composto por motoristas, cobradores e fiscais, pessoal de manutenção e pessoal administrativo, considerando seus salários, benefícios e os encargos sociais incidentes sobre a folha de pagamento.

Os encargos sociais têm sua origem na CLT, na Constituição Federal de 1988, em leis específicas e nas convenções coletivas de trabalho. Vale ressaltar que existe uma polêmica quanto à definição sobre o cálculo do custo de encargos sociais para os empregadores. Uma constatação de Pastore (1996), que se verifica até os dias de hoje, é a de que, em determinados casos, os encargos sociais podem chegar até $102 \%$ do salário pago ao trabalhador. Fiocca (1996), em resposta, afirma que aquele valor representa um "instrumento contábil", válido apenas para se saber qual o custo da hora efetivamente trabalhada. Segundo a Nota Técnica DT 18/2007, isso se deve ao fato de se considerar:

[...] apenas a remuneração relativa ao tempo em que $\mathrm{o}$ trabalhador permanece efetivamente à disposição do empregador, considera como encargo social o pagamento de domingos e feriados e o de outras ausências remuneradas, como aquelas cujo motivo é doença, gala ou nojo (além de férias, $13^{\circ}$ salário e contribuições relacionadas ao pagamento de todas as ausências citadas). (AGERGS, 2007b, p. 67).

Quanto aos sistemas de transporte em estudo, a composição dos encargos sociais, de forma geral, é representada pelo

Quadro 1, a seguir:

Quadro 1 - Incidências sobre a folha de pagamento dos serviços de transporte de passageiros

\begin{tabular}{|l|r|}
\hline \multicolumn{1}{|c|}{ GRUPO A - Incidem sobre a Folha de Pagamento: decorrentes de Legislação Federal } & $\%$ \\
\hline 1. Instituto Nacional do Seguro Social (INSS) & 20,00 \\
\hline 2. Acidentes de trabalho & 3,00 \\
\hline 3. Salário-educação & 2,50 \\
\hline 4. Instituto Nacional de Colonização e Reforma Agrária (INCRA) & 0,20 \\
\hline 5. Serviço Nacional de Aprendizagem do Transporte (SENAT) & 1,00 \\
\hline 6. Serviço Social do Transporte (SEST) & 1,50 \\
\hline 7. Serviço Brasileiro de Apoio às Micro e Pequenas Empresas (SEBRAE) & 0,60 \\
\hline 8. Programa de Controle Médico de Saúde Ocupacional (PCMSO) & 0,50 \\
\hline 9. Fundo de Garantia por Tempo de Serviço (FGTS) & 8,00 \\
\hline Subtotal & $\mathbf{3 7 , 3 0}$ \\
\hline & \\
\hline 10. Abono de férias & 2,78 \\
\hline 11. Aviso prévio trabalhado & 0,11 \\
\hline 12. Licença-paternidade & 0,04 \\
\hline 13. Licença-funeral & 0,01 \\
\hline 14. Licença-casamento & 0,02 \\
\hline 15. Décimo terceiro salário & 8,33
\end{tabular}




\begin{tabular}{|c|c|}
\hline 16. Adicional noturno & 1,31 \\
\hline Subtotal & 12,60 \\
\hline \multicolumn{2}{|c|}{ GRUPO C - CLT e Lei 7.238/84 } \\
\hline 17. Depósito por rescisão & 3,60 \\
\hline 18. Aviso prévio indenizado & 1,81 \\
\hline Subtotal & 5,41 \\
\hline \multicolumn{2}{|c|}{ GRUPO D - Incidência Cumulativa } \\
\hline 19. Incidência do Grupo A sobre o Grupo B & 4,70 \\
\hline TOTAL & 60,01 \\
\hline
\end{tabular}

Fonte: Adaptado de Informação DT 08/2013 (AGERGS, 2013a, p. 18).

Para fins da composição do cálculo tarifário, os custos de pessoal são transferidos para a planilha em forma de Fator Agregado Anual (parâmetro). Conforme a Nota Técnica 18/2007, o fator de utilização, para cada categoria de pessoal, é apurado pela divisão do número de pessoal de determinada atividade (operacional, manutenção e administrativo) e a frota operacional. Dessa forma, apurase quanto se aloca de pessoal para cada unidade da frota. Já o fator hora extra é apurado a partir da divisão da rubrica "Horas Extras" do balancete padrão remetido pelas empresas pela rubrica "Salários" do balancete padrão. O fator encargos considera os valores dos encargos sociais de cada sistema (AGERGS, 2007b).

Os tributos (impostos, contribuições e taxas) que incidem sobre a receita operacional das empresas operadoras também devem ser incluídos no cálculo tarifário. Assim, a planilha de cálculo considera a contribuição previdenciária sobre a receita bruta referente à desoneração da folha de pagamento, além de PIS, COFINS, ICMS, taxa do sistema estadual de transporte metropolitano - SETM (controlado pela METROPLAN), taxa de regulação da AGERGS e comissões às estações rodoviárias. Os tributos citados devem ser incluídos na tarifa, pois fazem parte da própria base de cálculo. A inclusão na tarifa é realizada por meio do Fator de Incidência Tributária que, aplicado sobre o custo da tarifa, resulta em um coeficiente tarifário que possibilite ao prestador de serviço público um retorno líquido idêntico àquele percebido anteriormente à tributação.

\subsection{Influências no tratamento contábil,} no ponto de equilíbrio contábil, e giro do ativo das prestadoras de serviços

Quanto ao tratamento contábil dado aos tributos citados, a CPRB passa a ser tratada da mesma forma que o PIS, COFINS e ICMS, pois é deduzida da receita bruta da empresa. Cabe ressaltar que ambos os lançamentos contábeis possuem o crédito em comum no passivo circulante, todavia suas contrapartidas são 
realizadas em etapas diferentes da

(DRE), conforme se observa no Quadro 2.

Demonstração do Resultado do Exercício

Quadro 2 - Estrutura da DRE das empresas prestadoras de serviços

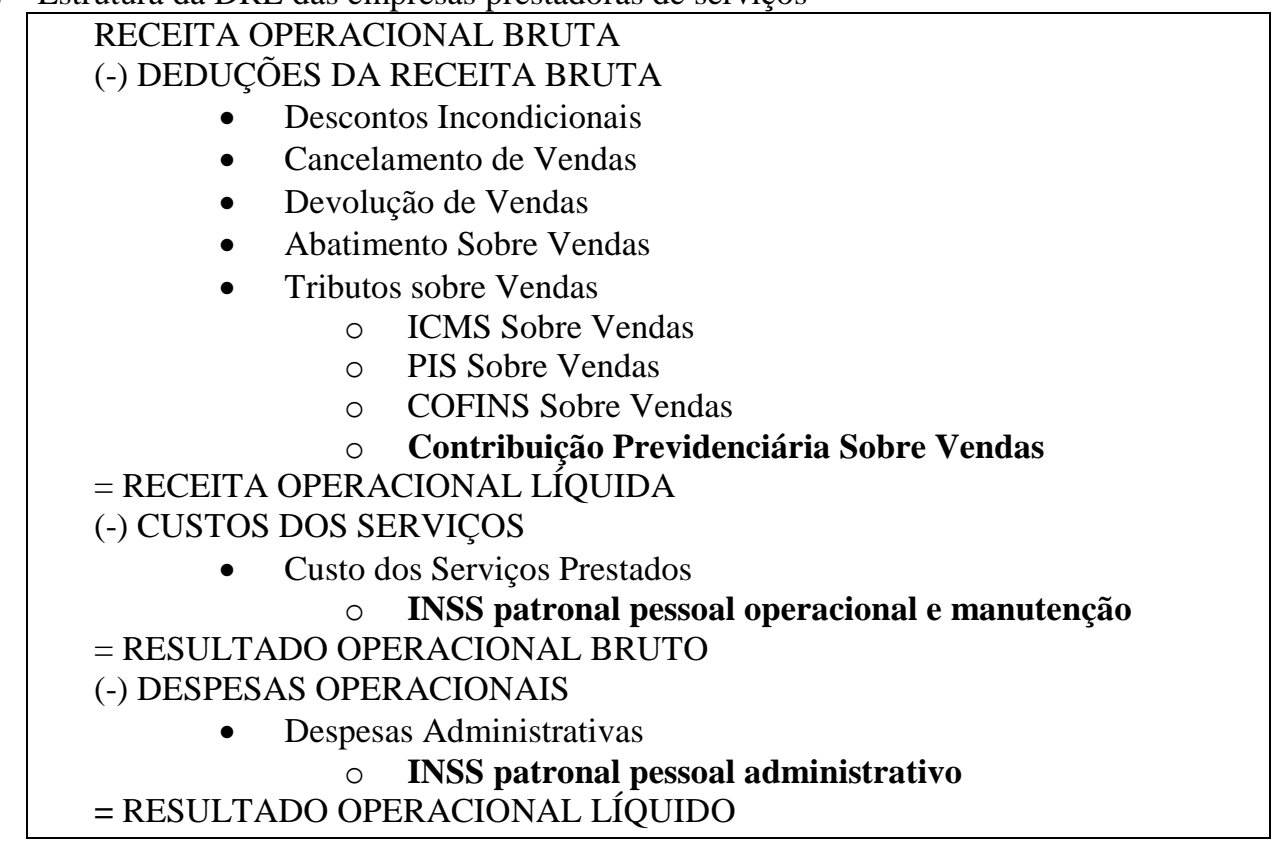

Fonte: Elaborado com base em Martins (2010) e Assaf Neto (2010).

Os encargos e os salários são custos

fixos, e sua modificação afeta o custo da mercadoria ou serviço, como observado no Quadro 2. Há também os custos variáveis que, ainda segundo Martins (2010), são custos que estão atrelados ao volume de produção: quanto maior a quantidade produzida ou quanto maiores os serviços prestados, maior o consumo. Esse tipo de custo não sofre influência direta em função da alteração da contabilização demonstrada.
Algumas ferramentas de avaliação de desempenho e de tomada de decisão são afetadas pela redução dos custos fixos e o consequente aumento das disponibilidades da empresa. Como exemplo, pode-se citar a margem de contribuição unitária, a razão de contribuição, o ponto de equilíbrio contábil e o giro do ativo.

De acordo com Bornia (2010), quase todas as aplicações de custos para decisões de curto prazo embasam-se nos conceitos de Margem de Contribuição Unitária (MCU) e Razão de Contribuição 
(RC). Bornia (2010, p. 55) esclarece que "a margem de contribuição unitária representa a parcela do preço de venda que resta para a cobertura dos custos e despesas fixos e para a geração do lucro" e é representada pelo preço de venda menos o custo variável unitário. Já a razão de contribuição é a margem de contribuição unitária dividida pelo preço de venda e representa a mesma função da margem de contribuição, porém em termos percentuais. A diferença entre esses itens é que a margem de contribuição unitária está relacionada ao lucro do produto, ao passo que a razão de contribuição está ligada à rentabilidade (BORNIA, 2010). No mesmo enfoque, Eldenburg e Wolcott (2007) destacam que o ponto de equilíbrio contábil da empresa é o nível de vendas no qual as receitas cobrem os custos fixos e variáveis, resultando em um lucro nulo. Pode ser obtido pela razão entre os custos fixos e a margem de contribuição unitária. Sob esses preceitos, para as empresas que trabalham com diversas linhas convencionais e regulares de transporte intermunicipal de passageiros, é praxe que se considere o número de linhas e serviços oferecidos para o cálculo do ponto de equilíbrio em relação ao número de viagens necessárias para a cobertura de seus custos.

Outro indicador afetado pelos gastos tributários é o giro do ativo. Este indicador estima o número de vezes que o ativo total da empresa girou em determinado período em função das vendas concretizadas. Quanto maior se apresentar esse giro, melhor terá sido a performance da empresa, por meio de um melhor retorno de suas aplicações (ASSAF NETO, 2010, p. 211). Esse indicador relaciona as receitas operacionais obtidas pela empresa com seu ativo total de forma a demonstrar seu giro, sendo esse valor obtido pela razão entre as receitas operacionais e o ativo total.

\section{PRODUÇÃO CIENTÍFICA SOBRE A TEMÁTICA ESTUDADA}

A contabilidade tributária é ramo da contabilidade que tem por objetivo aplicar na prática conceitos, princípios e normas contábeis e da legislação tributária, de forma simultânea e adequada na apuração dos gastos tributários (ELDENBURG, WOLCOTT, 2007). Nesse contexto, a desoneração tributária tem sido objeto de estudo por pesquisadores da área contábil. A seguir, citam-se alguns estudos aplicados no segmento e na temática enfocada.

Ressalta-se o estudo de Freitas et al. (2013), que teve o objetivo de efetuar um levantamento da carga tributária incidente sobre empresas vinculadas ao transporte público, avaliando como a desoneração tributária contribuiria para o 
aumento da participação do transporte público por ônibus nas viagens realizadas no país. Os autores evidenciam que a situação do Brasil é oposta à de países desenvolvidos, que subsidiam, em média, $50 \%$ da receita do sistema.

Sob o mesmo enfoque, um estudo de Cardoso, Souza e Domingues (2014), usando um modelo de equilíbrio geral computável, avaliou os impactos da desoneração da folha de pagamento no Brasil. O estudo constata que há efeitos positivos no crescimento no longo prazo da economia, da educação, do emprego, do PIB e do consumo das famílias. Entretanto, segundo nota técnica editada pelo Departamento Intersindical de Estatística e Estudos Socioeconômicos (DIEESE), as renúncias fiscais devem ser monitoradas e avaliadas (DIEESE, 2012). Sob esse enfoque, pode-se observar que, em decorrência da crise econômica no ano de 2015, o governo brasileiro, tendo como justificativa o atual cenário econômico - o aumento do déficit da previdência e necessidades de ajustes a curto e médio prazo nas contas fiscais - editou o projeto de Lei majorando as alíquotas vigentes. A ausência de evidências de efeitos positivos da desoneração da folha sobre o nível de emprego, produtividade e exportação foi a justificativa apresentada (PINTO; AFONSO, 2015).
Evidencia-se também outro estudo, realizado por Nardelli, Terres e Fidelix (2014), que buscaram analisar os reflexos da desoneração tributária, utilizando-se de metodologia de estudo multicaso em duas empresas do setor industrial pesqueiro e duas empresas do setor hoteleiro. Nesse estudo, não foi possível identificar um reflexo padrão entre as empresas, sendo uma beneficiada, uma onerada, e outras duas obtiveram resultados semelhantes, sendo levemente oneradas.

Na mesma linha de estudos, Santos, Brinckmann e Camargo (2014), por sua vez, realizaram uma análise comparativa da substituição da Contribuição Previdenciária Patronal (CPP) pela CPRB quanto ao impacto tributário causado nas empresas listadas na Bolsa de Valores de São Paulo (BM\&FBOVESPA), obrigadas ao seu cálculo em 2012. Por meio da análise das 30 empresas selecionadas, constataram que, em $93 \%$ das empresas analisadas, a CPRB desonerou a carga previdenciária em 2012; contudo, para 7\%, a alteração ocasionou uma oneração.

Com base nas informações expostas sobre as características e o funcionamento do sistema de transportes, o modo de cálculo das tarifas e o funcionamento da desoneração da folha, foi possível realizar um panorama sobre as questões que envolvem este importante meio de deslocamento da sociedade. Além disso, os 
reflexos nos âmbitos financeiros $\mathrm{e}$ contábeis das questões de oneração ou desoneração tributária também foram evidenciados.

\section{METODOLOGIA}

A pesquisa realizada neste estudo é classificada quanto aos seguintes aspectos: (a) pela forma de abordagem do problema; (b) de acordo com seus objetivos; e (c) com base nos procedimentos técnicos utilizados.

Quanto à forma de abordagem do problema, esta pesquisa classifica-se como qualitativa em função de analisar o impacto que as desonerações tributárias causam nos diversos setores da sociedade e, neste estudo, observada sua influência nas tarifas de transportes. Sob o aspecto qualitativo, esta pesquisa cerca-se da "forma de experimentação empírica, a partir de análises feitas de forma detalhada, abrangente, consistente e coerente, assim como na argumentação lógica das ideias" (MICHEL, 2009, p. 37).

Quanto aos objetivos, a pesquisa caracteriza-se como exploratória e descritiva. Segundo Gil (2008), a pesquisa exploratória é desenvolvida no sentido de proporcionar uma visão geral acerca de determinado fato ainda pouco estudado: o caso específico das agências reguladoras. A pesquisa descritiva tem como principal objetivo descrever características de determinada população ou fenômeno, ou o estabelecimento de relação entre as variáveis. Comumente, utiliza técnicas padronizadas para a coleta de dados. Os resultados de uma pesquisa exploratória podem contribuir na identificação de relações existentes entre as variáveis estudadas de determinada população (GIL, 2008).

Por fim, no que se refere aos procedimentos técnicos utilizados, o presente estudo classifica-se como pesquisa documental, com a coleta de documentos disponibilizados no website da AGERGS e na intranet, além de consultas bibliográficas para embasamento teórico, e as respectivas legislações que envolvem a temática. Gil (2008) ressalta que a pesquisa documental se baseia em materiais ainda sem tratamento analítico, ou seja, são dados brutos. Para a realização deste estudo documental e para atingir o objetivo proposto, necessitou-se obter diversos relatórios técnicos, notas técnicas e processos administrativos onde constam os cálculos das revisões e dos reajustes tarifários, vinculando-os com a legislação pertinente às questões de estudo. $\mathrm{O}$ desenvolvimento do estudo concentra-se nas entidades de transporte rodoviário que realizaram reajuste com base na Lei Federal n. ${ }^{\circ}$ 12.546/2011 (BRASIL, 2011). 


\section{ANÁLISE E DISCUSSÃO DOS RESULTADOS}

Nessa etapa do estudo, são calculados os valores com a nova sistemática e a anterior, verificando se houve aumento ou redução no coeficiente tarifário de cada setor calculado. Posteriormente, efetua-se uma análise comparativa com os resultados obtidos. Também são analisados indicadores como a margem de contribuição unitária, a razão de contribuição e o giro do ativo, considerando-se os dois cenários, ou seja, com desoneração e sem desoneração.

\subsection{Resultados dos cálculos tarifários desconsiderando os efeitos da desoneração}

Tabela 1 - Coeficiente Tarifário (COET) por sistema - Sem Desoneração (em R\$/Km) (2013/2014)

\begin{tabular}{lr}
\hline Região Metropolitana de Porto Alegre (RMPA) & 0,141064 \\
Região Metropolitana da Serra Gaúcha (RMSG) & 0,155465 \\
Aglomeração Urbana do Litoral Norte (AULINOR) & 0,167008 \\
Aglomeração Urbana do Sul (AUSUL) & 0,138602 \\
Longo Curso (LC) & 0,168563 \\
\hline
\end{tabular}

Fonte: Elaborado pelos autores (2015).

Observa-se na Tabela 1 que o sistema de longo curso é o que apresenta o maior coeficiente tarifário, seguido pelo sistema da AULINOR. Por outro lado, o sistema que consome menos recursos por quilômetro rodado é o da AUSUL, fato que torna as tarifas aplicadas nas linhas da região mais acessíveis financeiramente.
A planilha tarifária é composta por todos os itens de custos fixos e variáveis necessários ao funcionamento do sistema; juntamente com os parâmetros de consumo e o preço unitário de cada item, obtém-se o custo quilométrico para cada item de custo. Após a aplicação dos indicadores e dos tributos incidentes, obtém-se o coeficiente tarifário, que é o resultado de todo o estudo envolvido, e é com esse que se obtém o valor da tarifa de cada linha de ônibus. A seguir, na Tabela 1, pode-se observar o coeficiente tarifário de cada sistema, desconsiderando os efeitos da desoneração tributária. 
quanto nos outros) estão grifados em vermelho.

Tabela 2 - Sistema Aglomeração Urbana do Sul (AUSUL) sem desoneração e o coeficiente tarifário (2013/2014)

\begin{tabular}{llllll}
\hline Insumos & Unidade & Parâmetro & Valor $(\mathrm{R} \$)$ & $\mathrm{R} \$ / \mathrm{Km}$ & Part.\% \\
\hline Óleo diesel & $\mathrm{L} / \mathrm{Km}$ & 0,339017 & 1,7763 & 0,6022 & $13,03 \%$ \\
Óleo de transmissão & $\mathrm{L} / \mathrm{Km}$ & 0,00009 & 6,5000 & 0,0006 & $0,01 \%$ \\
Óleo caixa & $\mathrm{L} / \mathrm{Km}$ & 0,000274 & 6,3800 & 0,0017 & $0,04 \%$ \\
Óleo motor & $\mathrm{L} / \mathrm{Km}$ & 0,001096 & 5,8400 & 0,0064 & $0,14 \%$ \\
Rodagem (pneu + recapagem) & Pneu/Km & 0,000048 & $1.582,0000$ & 0,0759 & $1,64 \%$ \\
Peças e acessórios & \% veículo & 0,031973 & $326.107,0000$ & 0,2507 & $5,43 \%$ \\
\hline Custos variáveis & & & & $\mathbf{0 , 9 3 7 6}$ & $\mathbf{2 0 , 2 9 \%}$ \\
\hline Depreciação da frota & \% veículo & 0,054237 & $316.615,0000$ & 0,4129 & $8,94 \%$ \\
Remuneração da frota & \% veículo & 0,046937 & $316.615,0000$ & 0,3574 & $7,73 \%$ \\
Remuneração outros ativos & \% veículo & 0,003 & $326.107,0000$ & 0,0235 & $0,51 \%$ \\
Despesas administrativas & \% veículo & 0,019816 & $326.107,0000$ & 0,1554 & $3,36 \%$ \\
Motorista: remuneração e encargos & H/veic./ano & 27,745558 & $1.760,0000$ & 1,1742 & $25,41 \%$ \\
Benefícios dos motoristas & & 15,840377 & 106,0000 & 0,0404 & $0,87 \%$ \\
Cobrador: remuneração e encargos & H/veic./ano & 26,20396 & $1.161,7000$ & 0,7320 & $15,84 \%$ \\
Benefícios dos cobradores & & 15,216284 & 106,0000 & 0,0388 & $0,84 \%$
\end{tabular}

Tabela 2 - Sistema Aglomeração Urbana do Sul (AUSUL) sem desoneração e o coeficiente tarifário (2013/2014) (cont.)

\begin{tabular}{|c|c|c|c|c|c|}
\hline Fiscal: remuneração e encargos & H/veic./ano & 1,578916 & $1.537,1900$ & 0,0584 & $1,26 \%$ \\
\hline Benefícios dos fiscais & & 0,986761 & 106,0000 & 0,0025 & $0,05 \%$ \\
\hline Pessoal manutenção & $\begin{array}{l}\% \text { pessoal } \\
\text { operacional }\end{array}$ & 0,107734 & & 0,2205 & $4,77 \%$ \\
\hline Pessoal administração & $\begin{array}{l}\% \text { pessoal } \\
\text { operacional }\end{array}$ & 0,042968 & & 0,0879 & $1,90 \%$ \\
\hline \multirow[t]{16}{*}{ Custos fixos } & & & & 3,3039 & $71,49 \%$ \\
\hline & & & otal (unitário) & 4,2415 & \\
\hline & & & Tributos & 0,3799 & $8,22 \%$ \\
\hline & & Total c & utos (unitário) & 4,6213 & $100,00 \%$ \\
\hline & & & & \multicolumn{2}{|c|}{ Indicadores e tributos } \\
\hline & & & \multicolumn{2}{|c|}{ Lotação } & 55,46 \\
\hline & & & \multicolumn{2}{|c|}{ Aproveitamento } & $60,12 \%$ \\
\hline & & Valor do $\mathrm{p}$ & nédio anual $(\mathrm{k}$ & & $41.586,11$ \\
\hline & & & \multicolumn{2}{|c|}{ Tributo } & $\%$ \\
\hline & & & \multicolumn{2}{|c|}{ PIS } & 0,65 \\
\hline & & & \multicolumn{2}{|c|}{ COFINS } & 3,00 \\
\hline & & & \multicolumn{2}{|c|}{ ICMS } & 2,40 \\
\hline & & & \multicolumn{2}{|c|}{ SETM } & 1,26 \\
\hline & & & \multicolumn{2}{|c|}{ AGERGS } & 0,91 \\
\hline & & & \multicolumn{2}{|c|}{ Cont. Prev. } & - \\
\hline & & & \multicolumn{2}{|c|}{ Total } & 8,22 \\
\hline Coeficiente tarifário (cus & m total com & butos / (ap & nento x lotaçã & & 0,138602 \\
\hline
\end{tabular}

Fonte: Elaborado pelos autores, com base na informação DT 33/2013 (AGERGS, 2013b, p. 4).

No sistema da AUSUL, como se observa na Tabela 2 , os custos variáveis unitários representam $\mathrm{R} \$ 0,9376$, e os custos fixos unitários representam $\mathrm{R} \$$ 3,3039 do coeficiente tarifário, ou seja,
$20,29 \%$ e $71,49 \%$, respectivamente. O restante, $8,22 \%$ são os tributos devidos pelas empresas do sistema, o que, em reais, representa $\mathrm{R} \$ 0,3799$ por quilômetro rodado. O valor final de $\mathrm{R} \$ 4,6213$ é 
confrontado com os indicadores de aproveitamento e lotação, de modo a se chegar ao coeficiente tarifário de $\mathrm{R} \$$ 0,138602 para o sistema.

\subsection{Resultados dos cálculos tarifários} considerando os efeitos da desoneração

A fim de aplicar a nova sistemática de cálculo, o procedimento adotado foi recalcular o Fator Agregado Anual, desconsiderando o INSS patronal de $20 \%$ do Fator de Encargos Sociais, e inserir no Fator de Incidência Tributária os $2 \%$ referentes à CPRB. As Tabelas 3 e 4, referentes ao sistema da aglomeração urbana do sul (AUSUL), apresentam o resultado alterado do Fator Agregado Anual, obtido pela multiplicação dos fatores e por doze. Esse produto representa um valor base, com o fim de acrescentar estes custos, quando multiplicado na planilha de custos.

Tabela 3 - Cálculo do Fator Agregado Anual sem a desoneração da folha (2013/2014)

\begin{tabular}{lcccc}
\hline & $\begin{array}{c}\text { Fator de } \\
\text { Utilização }\end{array}$ & $\begin{array}{c}\text { Fator de Hora } \\
\text { Extra }\end{array}$ & $\begin{array}{c}\text { Fator de Encargos } \\
\text { Sociais }\end{array}$ & $\begin{array}{c}\text { Fator Agregado } \\
\text { Anual }\end{array}$ \\
\hline Motoristas & 1,320031 & 1,0947 & 1,6001 & $\mathbf{2 7 , 7 4 5 5 5}$ \\
Cobradores & 1,268024 & 1,0762 & 1,6001 & $\mathbf{2 6 , 2 0 3 9 6}$ \\
Fiscais & 0,08223 & 1 & 1,6001 & $\mathbf{1 , 5 7 8 9 1 5}$ \\
\hline
\end{tabular}

Fonte: Elaborado pelos autores com base na informação DT 33/2013 (AGERGS, 2013b, p. 3).

Tabela 4 - Cálculo do Fator Agregado Anual com a desoneração da folha (2013/2014)

\begin{tabular}{|c|c|c|c|c|}
\hline & $\begin{array}{l}\text { Fator de } \\
\text { Utilização }\end{array}$ & $\begin{array}{c}\text { Fator de Hora } \\
\text { Extra }\end{array}$ & $\begin{array}{c}\text { Fator de Encargos } \\
\text { Sociais } \\
\end{array}$ & $\begin{array}{c}\text { Fator Agregado } \\
\text { Anual } \\
\end{array}$ \\
\hline Motoristas & 1,320031 & 1,0947 & 1,4001 & 24,27757 \\
\hline Cobradores & 1,268024 & 1,0762 & 1,4001 & 22,92867 \\
\hline Fiscais & 0,08223 & 1 & 1,4001 & 1,381563 \\
\hline
\end{tabular}

Quanto ao Fator de Incidência

Tributária, o valor de $\mathrm{R} \$ 0,3799$ por quilômetro rodado, utilizando-se uma alíquota de $8,22 \%$, passa a ser de $\mathrm{R} \$$ 0,4507 por quilômetro rodado para uma alíquota de 10,22\%, como se pode observar na Tabela 5. Na segunda coluna, são apresentados os percentuais e valores, desconsiderando-se a contribuição previdenciária, ao passo que a terceira coluna demonstra os valores, considerando a contribuição previdenciária.

Tabela 5 - Alteração no Fator de Incidência Tributária no sistema da AUSUL (2013/2014)

\begin{tabular}{lll}
\hline $\begin{array}{l}\text { Descrição da tributação e contribuição } \\
\text { previdenciária por km }\end{array}$ & $\begin{array}{l}\text { Percentuais e valores sem } \\
\text { contribuição previdenciária }\end{array}$ & $\begin{array}{l}\text { Percentuais e valores com } \\
\text { contribuição previdenciária }\end{array}$ \\
\hline $\begin{array}{l}\text { Tributos sobre o faturamento: PIS, COFINS, } \\
\text { ICMS, SETM, AGERGS }\end{array}$ & $8,22 \%$ & $8,22 \%$ \\
Contribuição previdenciária & - & $\mathbf{2 , 0 0} \%$ \\
\hline TOTAL & $\mathbf{8 , 2 2} \%$ & $\mathbf{1 0 , 2 2} \%$ \\
\hline Subtotal custo unitário por km & $\mathrm{R} \$ 4,24$ & $\mathrm{R} \$ 3,96$ \\
Tributos por Km (unitário) & $\mathrm{R} \$ 0,38$ & $\mathrm{R} \$ 0,45$ \\
\hline
\end{tabular}


Total do custo unitário com tributos por $\mathrm{km} \quad \mathrm{R} \$ 4,62$

$\mathrm{R} \$ 4,41$

Fonte: Elaborado pelos autores.

Como exemplo, a Tabela 6 apresenta a planilha de cálculo do sistema da AUSUL com a devida alteração de sistemática de cálculo (campos grifados em vermelho) aplicada nesse sistema e nos outros sistemas em estudo.

Tabela 6 - Sistema Aglomeração Urbana do Sul (AUSUL) com desoneração e o coeficiente tarifário (2013/2014)

\begin{tabular}{|c|c|c|c|c|c|}
\hline Insumos & Unidade & Parâmetro & Valor $(\mathrm{R} \$)$ & $\mathrm{R} \$ / \mathrm{Km}$ & Part.\% \\
\hline Óleo diesel & $\mathrm{L} / \mathrm{Km}$ & 0,339017 & 1,7763 & 0,6022 & $13,66 \%$ \\
\hline Óleo de transmissão & $\mathrm{L} / \mathrm{Km}$ & 0,00009 & 6,5000 & 0,0006 & $0,01 \%$ \\
\hline Óleo caixa & $\mathrm{L} / \mathrm{Km}$ & 0,000274 & 6,3800 & 0,0017 & $0,04 \%$ \\
\hline Óleo motor & $\mathrm{L} / \mathrm{Km}$ & 0,001096 & 5,8400 & 0,0064 & $0,15 \%$ \\
\hline Rodagem (pneu + recapagem) & Pneu/Km & 0,000048 & $1.582,0000$ & 0,0759 & $1,72 \%$ \\
\hline Peças e acessórios & $\%$ veículo & 0,031973 & $326.107,0000$ & 0,2507 & $5,69 \%$ \\
\hline Custos variáveis & & & & 0,9376 & $21,27 \%$ \\
\hline Depreciação da frota & $\%$ veículo & 0,054237 & $316.615,0000$ & 0,4129 & $9,36 \%$ \\
\hline \multicolumn{6}{|c|}{ Tabela 6 - Sistema Aglomeração Urbana do Sul (AUSUL) com desoneração e o coeficiente tarifário (2013/2014) (cont.) } \\
\hline Remuneração da frota & \% veículo & 0,046937 & $316.615,0000$ & 0,3574 & $8,10 \%$ \\
\hline Remuneração outros ativos & \% veículo & 0,003 & $326.107,0000$ & 0,0235 & $0,53 \%$ \\
\hline Despesas administrativas & \% veículo & 0,019816 & $326.107,0000$ & 0,1554 & $3,52 \%$ \\
\hline Motorista: remuneração e encargos & H/veic./ano & 24,277573 & $1.760,0000$ & 1,0275 & $23,30 \%$ \\
\hline Benefícios dos motoristas & & 15,840377 & 106,0000 & 0,0404 & $0,92 \%$ \\
\hline Cobrador: remuneração e encargos & H/veic./ano & 22,928673 & $1.161,7000$ & 0,6405 & $14,53 \%$ \\
\hline Benefícios dos cobradores & & 15,216284 & 106,0000 & 0,0388 & $0,88 \%$ \\
\hline Fiscal: remuneração e encargos & H/veic./ano & 1,381563 & $1.537,1900$ & 0,0511 & $1,16 \%$ \\
\hline Benefícios dos fiscais & & 0,986761 & 106,0000 & 0,0025 & $0,06 \%$ \\
\hline Pessoal manutenção & $\begin{array}{l}\% \text { pessoal } \\
\text { operacional }\end{array}$ & 0,107734 & & 0,1940 & $4,40 \%$ \\
\hline Pessoal administração & $\begin{array}{l}\% \text { pessoal } \\
\text { operacional }\end{array}$ & 0,042968 & & 0,0774 & $1,75 \%$ \\
\hline \multirow[t]{17}{*}{ Custos fixos } & & & & 3,0213 & $68,51 \%$ \\
\hline & & & Subtotal & $3, \mathbf{3 , 9 5 8 9}$ & \\
\hline & & & Tributos & 0,4507 & $10,22 \%$ \\
\hline & & & al com tributos & 4,4095 & $100,00 \%$ \\
\hline & & & & \multicolumn{2}{|c|}{ Indicadores e tributos } \\
\hline & & & \multicolumn{2}{|c|}{ Lotação } & $\mathbf{5 5 , 4 6}$ \\
\hline & & & \multicolumn{2}{|c|}{ Aproveitamento } & $60,12 \%$ \\
\hline & & Valor do per & \multicolumn{2}{|c|}{ rso médio anual (km) } & 41.586,11 \\
\hline & & & \multicolumn{2}{|c|}{ Tributo } & $\%$ \\
\hline & & & \multicolumn{2}{|c|}{ PIS } & 0,65 \\
\hline & & & \multicolumn{2}{|c|}{ COFINS } & 3,00 \\
\hline & & & \multicolumn{2}{|c|}{ ICMS } & 2,40 \\
\hline & & & \multicolumn{2}{|c|}{ SETM } & 1,26 \\
\hline & & & \multicolumn{2}{|c|}{ AGERGS } & 0,91 \\
\hline & & & \multicolumn{2}{|c|}{ Cont. Prev. } & $\mathbf{2 , 0 0}$ \\
\hline & & & \multicolumn{2}{|c|}{ Total } & 10,22 \\
\hline & \multicolumn{4}{|c|}{ Coeficiente tarifário (custo km total com tributos / (aproveitamento x lotação)) } & $\mathbf{0 , 1 3 2 2 5 0}$ \\
\hline
\end{tabular}

Fonte: Adaptado de Informação DT 33/2013 (AGERGS, 2013b, p. 4).

Como se pode observar, houve uma redução no valor do coeficiente tarifário calculado que anteriormente apresentava o valor de $\mathrm{R}$ \$ 0,138602 por quilômetro na 
Tabela 2, passando ao valor de $\mathrm{R} \$ 0,132250$ por quilômetro na Tabela 6 , fato que representa uma redução de $4,58 \%$ para cada quilômetro rodado no sistema AUSUL.

\subsection{Análise comparativa dos efeitos da desoneração sobre os custos}

Tabela 7 - Comparação dos coeficientes tarifários dos sistemas com e sem desoneração (2013/2014)

\begin{tabular}{lccc}
\hline \multicolumn{1}{c}{ Sistema } & $\begin{array}{c}\text { Sem desoneração } \\
(\mathbf{R} \mathbf{k} / \mathbf{k m})\end{array}$ & $\begin{array}{c}\text { Com desoneração } \\
(\mathbf{R} \$ \mathbf{k m})\end{array}$ & Variação \\
\hline Região Metropolitana de Porto Alegre (RMPA) & 0,141064 & 0,137584 & $-2,47 \%$ \\
Região Metropolitana da Serra Gaúcha (RMSG) & 0,155465 & 0,151647 & $-2,46 \%$ \\
Aglomeração Urbana do Litoral Norte & 0,167008 & 0,162076 & $-2,95 \%$ \\
(AULINOR) & 0,138602 & 0,132249 & $-4,58 \%$ \\
Aglomeração Urbana do Sul (AUSUL) & 0,168563 & 0,163154 & $-3,21 \%$ \\
\hline Longo Curso (LC)
\end{tabular}

Fonte: Elaborado pelos autores.

Como evidenciado na Tabela 7, o sistema que obteve o maior impacto com variação negativa foi $o$ da AUSUL, seguido pelo de longo curso, com uma redução de $3,21 \%$ no valor total do quilômetro rodado. Os sistemas da RMPA
Reproduzindo essa sistemática de cálculo para os demais sistemas de transporte intermunicipal de passageiros, abrangidos pela competência da AGERGS, obtêm-se diferentes resultados em função das particularidades de cada sistema, a estrutura de custos das empresas que integram cada sistema, etc. Assim, quanto aos demais sistemas desonerados, pode-se observar, na Tabela 7, a comparação de todos os sistemas envolvidos no estudo.

\section{de}


Assim, pode-se observar, na Figura 2, que os cinco sistemas foram beneficiados pela alteração da sistemática de recolhimento da contribuição para a Previdência Social, cuja vigência ocorre a partir do mês de janeiro de 2013 até dezembro de 2014. Esse impacto da desoneração tributária corrobora o estudo de Freitas et al. (2013), que relata a notável influência dos tributos e encargos nas tarifas de ônibus das cidades brasileiras.

\subsection{Estimativa dos efeitos contábeis e} financeiros observados em uma empresa

A fim de apresentar, em termos financeiros e contábeis, as consequências de tais alterações nas empresas envolvidas nos sistemas, considera-se um percurso anual de $3.000 .000 \mathrm{~km}$, realizados por todas as linhas de uma prestadora de serviços de transportes, operando suas linhas exclusivamente em cada um dos sistemas estudados. Esse valor, multiplicado pelo coeficiente tarifário de cada sistema, pela respectiva lotação e pelo aproveitamento, resulta no valor total que a empresa poderia obter de receita, considerando apenas pagantes da modalidade de tarifa comum. Para esse percurso anual, o resultado seria uma economia de $\mathrm{R} \$ 635.355,95$ ao ano em impostos, operando no sistema da AUSUL, conforme se observa na Tabela 8 .

Tabela 8 - Comparação da receita anual estimada em uma prestadora do serviço de transporte (2013/2014)

\begin{tabular}{|c|c|c|c|c|c|}
\hline Sistema & Lotação & $\begin{array}{l}\text { Índice de } \\
\text { aproveitamento }\end{array}$ & $\begin{array}{l}\text { Receita sem } \\
\text { desoneração } \\
(\text { em } \mathbf{R} \$)\end{array}$ & $\begin{array}{l}\text { Receita com } \\
\text { desoneração } \\
(\mathrm{em} \mathbf{R} \$)\end{array}$ & $\begin{array}{l}\text { Economia } \\
\text { anual em } \\
\text { impostos } \\
(\text { em } \mathbf{R} \$)\end{array}$ \\
\hline $\begin{array}{l}\text { Região Metropolitana de } \\
\text { Porto Alegre (RMPA) }\end{array}$ & 48,08 & $64,15 \%$ & $13.052 .661,85$ & $12.730 .671,82$ & $321.990,03$ \\
\hline $\begin{array}{l}\text { Região Metropolitana da } \\
\text { Serra Gaúcha (RMSG) }\end{array}$ & 46 & $59,11 \%$ & $12.681 .599,13$ & $12.370 .129,11$ & $311.470,02$ \\
\hline $\begin{array}{l}\text { Aglomeração Urbana do } \\
\text { Litoral Norte } \\
\text { (AULINOR) }\end{array}$ & 40 & $55,19 \%$ & $11.060 .612,39$ & $10.733 .995,62$ & $326.616,76$ \\
\hline $\begin{array}{l}\text { Aglomeração Urbana do } \\
\text { Sul (AUSUL) }\end{array}$ & 55,46 & $60,12 \%$ & $13.863 .988,38$ & $13.228 .632,43$ & $635.355,95$ \\
\hline Longo Curso (LC) & 46 & $50,00 \%$ & $11.630 .830,37$ & $11.257 .629,97$ & $373.200,40$ \\
\hline
\end{tabular}

Fonte: Elaborado pelos autores (2105).

Esse alto valor na AUSUL, evidenciado na Tabela 8 , é consequência da maior capacidade de lotação dos ônibus desse sistema, fato que reflete um aumento na receita, embora o sistema da AUSUL apresente o menor coeficiente tarifário, como demonstrado na Tabela 7. Por outro lado, a RMSG foi o sistema que apresentou o menor valor, com uma economia de $\mathrm{R} \$ 311.470,02$ ao ano. O aproveitamento da RMSG é muito semelhante ao da AUSUL, contudo possui uma lotação 
menor, fato que reduz sua receita teórica e afeta a desoneração resultante.

Estes resultados alinham-se aos achados na pesquisa de Santos, Brinckmann e Camargo (2014), que constataram que a alteração da legislação, mediante a desoneração, trouxe um grande benefício financeiro para a maioria das empresas que foram contempladas com tal política do governo.

Um ponto a se analisar, diante desses fatos, são os efeitos que podem ocorrer no controle de custos das empresas e na relação de indicadores quando da análise de balanços. $\mathrm{O}$ coeficiente tarifário de cada sistema sofre uma redução diante da nova sistemática, como observado na Tabela 7, devido à desoneração. Como são dependentes desse valor, a Margem de Contribuição Unitária (MCU) e a Razão de Contribuição (RC) sofrem os mesmos efeitos, sendo o valor dos custos variáveis obtido por meio da mesma sistemática de cálculo adotada para o coeficiente tarifário, utilizando, no entanto, somente o valor dos custos variáveis. Observam-se esses efeitos na Tabela 9 a seguir.

Tabela 9 - Comparação da margem de contribuição unitária e da razão de contribuição em uma prestadora do serviço de transporte $(2013 / 2014)$

\begin{tabular}{lllllll}
\hline Sistema & $\begin{array}{l}\text { MCU sem } \\
\text { desoneração } \\
(\mathbf{e m ~ R} \mathbf{k m})\end{array}$ & $\begin{array}{l}\text { MCU com } \\
\text { desoneração } \\
(\mathbf{e m ~ R} \mathbf{k m})\end{array}$ & $\begin{array}{l}\text { Diferença } \\
\text { (em R\$/km) }\end{array}$ & $\begin{array}{l}\text { RC sem } \\
\text { desoneração }\end{array}$ & $\begin{array}{l}\text { RC com } \\
\text { desoneração }\end{array}$ & Diferença \\
\hline RMPA & 0,092000 & 0,086054 & 0,0059455 & $65 \%$ & $63 \%$ & $2,7 \%$ \\
\hline RMSG & 0,101840 & 0,095527 & 0,0063129 & $66 \%$ & $63 \%$ & $2,5 \%$ \\
AULINOR & 0,111200 & 0,103432 & 0,0077678 & $67 \%$ & $64 \%$ & $2,8 \%$ \\
\hline AUSUL & 0,099089 & 0,090613 & 0,0084747 & $71 \%$ & $69 \%$ & $3,0 \%$ \\
LC & 0,093469 & 0,085694 & 0,0077745 & $55 \%$ & $53 \%$ & $2,9 \%$ \\
\hline
\end{tabular}

Fonte: Elaborado pelos autores (2015).

Na Tabela 9, evidencia-se o maior impacto, tanto na Margem de Contribuição Unitária, quanto na Razão de Contribuição, no sistema da Aglomeração Urbana do Sul (AUSUL), com R\$ 0,0084747 e 3\%, respectivamente. A Região Metropolitana de Porto Alegre (RMPA) obteve a menor diferença na margem de contribuição unitária, com R\$ 0,0059455. Já a Região Metropolitana da Serra Gaúcha (RMSG) obteve a menor razão de contribuição, com 2,5\%. A variação observada nesses indicadores afeta diretamente o cálculo do ponto de equilíbrio contábil utilizado pelas empresas para estimar o número total de passageiros pagantes que contribuem para a cobertura dos custos fixos e variáveis do sistema. Assim, com a redução nos valores, é necessário menor número de passageiros pagantes para cobrir todos os custos da empresa.

Por outro lado, sobrando mais dinheiro no ativo, outros indicadores são afetados pela mudança, como o giro do 
ativo. Considerando que a mesma empresa possua um total de ativos de $\mathrm{R} \$$ 4.000.000,00, o indicador de giro do ativo é influenciado, conforme demonstrado na Tabela 10.

Tabela 10 - Comparação do giro do ativo estimado em uma prestadora do serviço de transporte (2013/2014)

\begin{tabular}{|c|c|c|c|}
\hline Sistemas & $\begin{array}{l}\text { Giro do ativo } \\
\text { sem desoneração }\end{array}$ & $\begin{array}{l}\text { Giro do ativo } \\
\text { com desoneração }\end{array}$ & Diferença \\
\hline Região Metropolitana de Porto Alegre (RMPA) & 3,26 & 3,18 & 0,08 \\
\hline Região Metropolitana da Serra Gaúcha (RMSG) & 3,17 & 3,09 & 0,08 \\
\hline $\begin{array}{l}\text { Aglomeração Urbana do Litoral Norte } \\
\text { (AULINOR) }\end{array}$ & 2,77 & 2,68 & 0,08 \\
\hline Aglomeração Urbana do Sul (AUSUL) & 3,47 & 3,31 & 0,16 \\
\hline Longo Curso (LC) & 2,91 & 2,81 & 0,09 \\
\hline
\end{tabular}

Fonte: Elaborado pelos autores (2015).

Na Tabela 10, o sistema da AUSUL foi o mais afetado, apresentando uma diferença de 0,16 vezes o total do ativo, seguido pelo sistema de longo curso, com 0,09 vezes. A RMPA, a RMSG e a AULINOR tiveram diferenças iguais, correspondendo a 0,08 vezes o total do ativo. Dessa forma, o aumento do ativo ocasiona uma redução no desempenho da empresa, embora seja apenas uma consequência dos recursos provenientes da desoneração.

\section{CONSIDERAÇÕES FINAIS}

Este estudo teve como objetivo analisar a influência da desoneração tributária no cálculo das tarifas de transportes intermunicipais, avaliando questões relativas ao equilíbrio econômico dos prestadores de serviços públicos, nos anos 2013 e 2014. Com base nos resultados expostos, observou-se que, para o setor de transportes, a desoneração tributária impactou na redução do valor do coeficiente tarifário de todos os sistemas e, consequentemente, o valor da tarifa cobrada nas linhas das empresas envolvidas. Cada cálculo tarifário teve um impacto diferente em função das particularidades envolvidas que devem ser consideradas, sendo estas responsáveis por influenciar isoladamente os resultados encontrados.

Neste estudo, observa-se que cada cálculo tarifário teve um impacto diferente em função das particularidades envolvidas que devem ser consideradas, sendo estas responsáveis por influenciar isoladamente os resultados encontrados. Por meio da análise de dados contábeis, conclui-se que a Aglomeração Urbana do Sul (AUSUL) foi o sistema mais desonerado do estudo, com uma redução de $4,58 \%$ no coeficiente tarifário. Por outro lado, os sistemas da Região Metropolitana de Porto Alegre (RMPA) e da Região Metropolitana da Serra Gaúcha (RMSG) apresentaram resultados muito semelhantes, com uma 
redução de $2,47 \%$ e $2,46 \%$, respectivamente.

Realizando uma estimativa dos custos com tributação em uma empresa do ramo estudado, constatou-se que a economia anual em impostos chega a $\mathrm{R} \$$ 635.355,95 no sistema da AUSUL. Já a RMSG apresentou o menor valor, com uma economia em decorrência da desoneração tributária prevista na legislação de R \$ 311.470,02 ao ano. Esses valores acabaram influenciando os demonstrativos financeiros das empresas devido à alteração da sistemática de recolhimento, além de impactar nas ferramentas de avaliação de desempenho e de tomada de decisão das empresas de transporte intermunicipal de passageiros estudadas.

A margem de contribuição unitária e a razão de contribuição tiveram um maior impacto no sistema da Aglomeração Urbana do Sul (AUSUL), representando R\$ 0,0084747 por quilômetro e $3 \%$ de redução, respectivamente. Para a RMPA, a diferença na margem de contribuição unitária foi de R \$ 0,0059455 e, na RMSG, a razão de contribuição reduziu $2,5 \%$. Essa variação afeta diretamente o cálculo do ponto de equilíbrio contábil dessas empresas, de modo que, com a redução nos valores, é necessário menor número de passageiros pagantes para cobrir os custos totais da empresa.
Quando da época da conclusão do presente estudo (Junho/2015), a Câmara dos Deputados analisava a majoração das alíquotas da Contribuição Previdenciária sobre a Receita Bruta (CPRB), devido ao ajuste fiscal necessário para melhorar as contas públicas. Trata-se de uma consequência da crise econômica vivenciada no Brasil, sendo que, para setores que recolhem $1 \%$ e $2 \%$, a alíquota proposta pelo projeto de Lei 863 (BRASIL, $2015)$ é de $2,5 \%$ e $4,5 \%$, respectivamente. A previsão do governo é de que a arrecadação aumente em $\mathrm{R}$ \$ 12,5 bilhões por ano com tal medida.

Este estudo contribui com a base de pesquisa referente à aplicação da desoneração tributária nas empresas de serviços de transportes, além de sintetizar os principais pontos da legislação e informar sobre práticas relevantes para a área contábil.

Para futuros trabalhos a serem realizados sobre o assunto, recomendam-se estudos que avaliem os impactos que o aumento de alíquotas da contribuição previdenciária sobre a receita bruta terão sobre as empresas envolvidas. Pode-se também estender o estudo para outros setores de transportes que se beneficiem deste incentivo, como, por exemplo, o setor hidroviário e o transporte rodoviário de passageiros municipal, interestadual e internacional. 


\section{REFERÊNCIAS}

AGÊNCIA ESTADUAL DE

REGULAÇÃO DOS SERVIÇOS

PÚBLICOS DELEGADOS DO RIO

GRANDE DO SUL. Diretoria de Tarifas e

Estudos Econômicos e Financeiros.

Informação DT 08/2013, de 08 de

fevereiro de 2013. Revisão Tarifária do

transporte Rodoviário da Aglomeração

Urbana do Nordeste (AUNE). Porto

Alegre, 2013a.

\section{AGÊNCIA ESTADUAL DE}

REGULAÇÃO DOS SERVIÇOS

PÚBLICOS DELEGADOS DO RIO

GRANDE DO SUL. Diretoria de Tarifas e

Estudos Econômicos e Financeiros.

Informação DT 33/2013, de 10 de junho

de 2013. Reajuste e revisão tarifária

extraordinária do transporte rodoviário

intermunicipal de passageiros da

Aglomeração Urbana do Sul (AUSUL).

Porto Alegre, 2013b.

AGÊNCIA ESTADUAL DE

REGULAÇÃO DOS SERVIÇOS

PÚBLICOS DELEGADOS DO RIO

GRANDE DO SUL. Diretoria de Tarifas e

Estudos Econômicos e Financeiros. Nota

Técnica DT 14/2007, de julho de 2007.

Metodologia e critérios gerais para definição e cálculo do Percurso Médio Anual (PMA) empregado na planilha tarifária do transporte intermunicipal de passageiros por ônibus da Aglomeração Urbana do Sul do Estado do Rio Grande do Sul - Região de Pelotas (AUSUL). Porto Alegre, 2007a. Disponível em:

<http://www.agergs.rs.gov.br/upload/nt140 7DT(1).pdf>. Acesso em: 20 jun. 2015.

AGÊNCIA ESTADUAL DE

REGULAÇÃO DOS SERVIÇOS

PÚBLICOS DELEGADOS DO RIO

GRANDE DO SUL. Diretoria de Tarifas e

Estudos Econômicos e Financeiros. Nota

Técnica DT 18/2007, de julho de 2007.

Metodologia e critérios gerais para definição e cálculo do Custo de Pessoal empregado na planilha tarifária do transporte intermunicipal de passageiros por ônibus da Aglomeração Urbana do Sul do Estado do Rio Grande do Sul - Região de Pelotas (AUSUL). Porto Alegre, 2007b. Disponível em:

<http://www.agergs.rs.gov.br/upload/nt180 7DT(1).pdf>. Acesso em: 20 jun. 2015.

AGÊNCIA ESTADUAL DE REGULAÇÃO DOS SERVIÇOS PÚBLICOS DELEGADOS DO RIO GRANDE DO SUL. Diretoria de Tarifas e Estudos Econômicos e Financeiros. Nota

Técnica DT 20/2007, de julho de 2007.

Metodologia e critérios gerais para definição e cálculo dos Tributos empregada na planilha tarifária do transporte intermunicipal de passageiros por ônibus da Aglomeração Urbana do Sul do Estado do Rio Grande do Sul - Região de Pelotas (AUSUL). Porto Alegre, 2007c. Disponível em:

<http://www.agergs.rs.gov.br/upload/nt200 7DT(1).pdf>. Acesso em: 20 jun. 2015.

AGÊNCIA ESTADUAL DE REGULAÇÃO DOS SERVIÇOS PÚBLICOS DELEGADOS DO RIO GRANDE DO SUL. Diretoria de Tarifas e Estudos Econômicos e Financeiros. Nota Técnica DT 03/2014, de outubro de 2014. Revisão tarifária da aglomeração urbana do litoral norte - AULINOR. Porto Alegre, 2014. Disponível em:

<http://www.agergs.rs.gov.br/upload/2014 1217131513nota_tecnica_dt_agergs_n0 3_2014_aulinor_v2.pdf>. Acesso em: 20 jun. 2015.

ASSAF NETO, Alexandre. Estrutura e análise de balanços: Um enfoque econômico-financeiro. 9 ed. São Paulo: Atlas, 2010.

BORNIA, Antônio Cezar. Análise gerencial de custos: aplicação em empresas modernas. 3. ed. São Paulo: Atlas, 2010. 
BRASIL. Constituição da República Federativa do Brasil de 1988. Brasília: Senado Federal, 1988. Disponível em: <http://www.planalto.gov.br/ccivil_03/con stituicao/constituicaocompilado.htm>. Acesso em: 10 jun. 2015.

BRASIL. Ministério da Fazenda.

Secretaria da Receita Federal do Brasil.

Demonstrativo dos gastos governamentais indiretos de natureza tributária (Gastos Tributários) - PLOA 2014. Brasília, 2014b. Disponível em: $<$ http://www.receita.fazenda.gov.br/public o/estudotributario/BensTributarios/2014/D GT2014.pdf>. Acesso em: 20 jun. 2015.

BRASIL. Ministério da Fazenda.

Secretaria da Receita Federal do Brasil. Desoneração da folha de pagamento Estimativa de renúncia e metodologia de cálculo. Brasília, 2014c. Disponível em: $<$ http://www.receita.fazenda.gov.br/public $\mathrm{o} /$ arre/RenunciaFiscal/Desoneracaodafolha .pdf>. Acesso em: 20 jun. 2015.

BRASIL. Presidência da República, Lei complementar N. 14, de 08 de junho de 1973. Estabelece as regiões metropolitanas de São Paulo, Belo Horizonte, Porto Alegre, Recife, Salvador, Curitiba, Belém e Fortaleza. Brasília, 1973. Disponível em: <http://www.planalto.gov.br/ccivil_03/leis/ lcp/Lcp14.htm>. Acesso em: 10 jun. 2015.

BRASIL. Presidência da República. Lei N. 8.212, de 24 de julho de 1991. Dispõe sobre a organização da Seguridade Social, institui Plano de Custeio e dá outras providências. Brasília, 1991. Disponível em:

<http://www.planalto.gov.br/ccivil_03/LEI S/L8212cons.htm>. Acesso em: 10 jun. 2015.

BRASIL. Presidência da República. Lei N. 12.546, de 14 de dezembro de 2011. Institui o Regime Especial de Reintegração de Valores Tributários para as Empresas Exportadoras (Reintegra); dispõe sobre a redução do Imposto sobre Produtos
Industrializados (IPI) à indústria automotiva; altera a incidência das contribuições previdenciárias devidas pelas empresas que menciona; e dá outras providências. Brasília, 2011. Disponível em:

<http://www.planalto.gov.br/ccivil_03/_at o2011-2014/2011/lei/112546.htm >.

Acesso em: 10 jun. 2015.

BRASIL. Presidência da República. Lei N. 12.587, de 03 de janeiro de 2012. Institui as diretrizes da Política Nacional de Mobilidade Urbana; revoga dispositivos dos Decretos-Leis nos 3.326, de 3 de junho de 1941, e 5.405, de 13 de abril de 1943, da Consolidação das Leis do Trabalho (CLT), aprovada pelo Decreto-Lei no 5.452 , de $1 .^{\circ}$ de maio de 1943 , e das Leis n. $^{\text {os }} 5.917$, de 10 de setembro de 1973 , e 6.261, de 14 de novembro de 1975; e dá outras providências. Brasília, 2012a.

Disponível em:

<http://www.planalto.gov.br/ccivil_03/_at o 2011-2014/2012/lei/112587.htm>.

Acesso em: 10 jun. 2015.

BRASIL. Presidência da República. Lei N. 12.715, de 17 de setembro de 2012 . Altera a alíquota das contribuições previdenciárias sobre a folha de salários devida pelas empresas que especifica; Altera a lei 12.546, de 14 de dezembro de 2011; e dá outras providências. Brasília, 2012b. Disponível em:

<http://www.planalto.gov.br/ccivil_03/_at o2011-2014/2012/lei/112715.htm>. Acesso em: 10 jun. 2015.

BRASIL. Presidência da República. Lei N. 13.043, de 13 de novembro de 2014.

Altera a Lei 12.546, de 14 de dezembro de 2011, 12.715, de 17 de setembro de 2012; e dá outras providências. Brasília, 2014a. Disponível em: <http://www.planalto.gov.br/ccivil_03/_at o2011-2014/2014/Lei/L13043.htm>. Acesso em: 10 jun. 2015.

BRASIL. Presidência da República. Projeto de Lei 863/2015. Para alterar a 
Lei $\mathrm{n}^{\circ} 12.546$, de 14 de dezembro de 2011, quanto à contribuição previdenciária sobre a receita bruta. Disponível em:

http://www.camara.gov.br/proposicoesWe b/fichadetramitacao?idProposicao $=105064$ 3. Acesso em: 23 jun. 2015.

CARDOSO, Débora Freire; SOUZA, Kênia Barreiro de; DOMINGUES, Edson Paulo. Medidas recentes de desoneração tributária no Brasil: uma análise de equilíbrio geral computável. In: Encontro de Economia Aplicada, I, 2014, Juiz de Fora. Anais eletrônicos... Disponível em: $<$ http://www.ufjf.br/encontroeconomiaapli cada/files/2014/05/MEDIDAS-

RECENTES-DE-

DESONERA\%C3\%87\%C3\%83O-

TRIBUT\%C3\%81RIA-NO-BRASIL-

UMA-AN\%C3\%81LISE-DE-

EQUIL\%C3\%8DBRIO-GERAL-

COMPUT\%C3\%81VEL.pdf $>$. Acesso em: 1. ${ }^{\mathrm{o}}$ jun. 2015.

\section{DEPARTAMENTO AUTÔNOMO DE} ESTRADAS DE RODAGEM (DAER). Resolução Regimental N$^{0} 5.295$ de 09 de dezembro de 2010. Porto Alegre, 2010. Disponível em:

$<$ http://www.daer.rs.gov.br/site/forca_dow nload.php?arquivo=arquivos/coletivos/arq uivo32_190.pdf>. Acesso em: 20 jun. 2015.

\section{DEPARTAMENTO INTERSINDICAL DE ESTATÍSTICA E ESTUDOS SOCIOECONÔMICOS (DIEESE). A} desoneração da folha de pagamentos: Avaliar para não perder. Nota técnica $\mathrm{N}^{\circ}$ 115, São Paulo, out. 2012. Disponível em: $<$ https://www.dieese.org.br/notatecnica/20 12/notaTec115desoneracao.pdf $>$. Acesso em: 1. ${ }^{\circ}$ jun. 2015.

ELDENBURG, Leslie G.; WOLCOTT, Susan K. Gestão de custos: como medir, monitorar e motivar o desempenho. Tradução: Luiz Antônio Fajardo Pontes. Rio de Janeiro: LTC, 2007.
FIOCCA, Demian. O que são encargos sociais. Folha de São Paulo, São Paulo, 31 jan. 1996. Disponível em: <http://www1.folha.uol.com.br/fsp/1996/1/ 31/dinheiro/2.html>. Acesso em: 07 jun. 2015 .

FREITAS, Matteus et al. Transporte urbano por ônibus: mapeamento da carga tributária e impacto nos custos. In: CONGRESSO BRASILEIRO DE TRANSPORTE E TRÂNSITO, 19, 2013, Brasília. Anais eletrônicos... Disponível em:

<http://www.antp.org.br/_5dotSystem/dow nload/dcmDocument/2013/10/07/2F29437 4-282E-45BC-AF11-

FD7C4001A362.pdf>. Acesso em: $1 .^{\circ}$ jun. 2015.

GIL, Antonio Carlos. Métodos e técnicas de pesquisa social. 6 . ed. São Paulo: Atlas, 2008.

MARTINS, Eliseu. Contabilidade de custos. 10. ed. São Paulo: Atlas, 2010.

MICHEL, Maria Helena. Metodologia e pesquisa científica em Ciências Sociais. 2. ed. São Paulo: Atlas, 2009. 241p.

NARDELLI, Francieli Knodt; TERRES, José Carlos; FIDELIX, Luiz Felipe. Os Reflexos da Desoneração da Folha de Pagamento para Fins de Contribuição Previdenciária: um Estudo Comparativo entre os Setores de Indústria e Serviço em empresas do Vale do Itajaí/SC. In: Congresso UFSC de Controladoria e Finanças, 5, 2014, Florianópolis. Anais eletrônicos... Disponível em: $<$ dvl.ccn.ufsc.br/congresso/anais/5CCF/20 140425064651.pdf $>$. Acesso em: 08 jun. 2015 .

PASTORE, José. A batalha dos encargos sociais. Folha de São Paulo, São Paulo, 28 fev. 1996. Disponível em: <http://www1.folha.uol.com.br/fsp/1996/2/ 28/dinheiro/11.html >. Acesso em: 07 jun. 2015. 
PINTO, Vilma da Conceição; AFONSO, José Roberto. Revisitando a desoneração que onera (empresas ou o governo) e que pune a produtividade. Instituto Brasileiro de Economia (FGV/IBRE), Rio de Janeiro, mar. 2015. Disponível em:

$<$ http://portalibre.fgv.br/lumis/portal/file/fil eDownload.jsp?fileId=8A7C82C54ADE62 52014C761F461756E2>. Acesso em: $1 .^{\circ}$ jun. 2015.

REHBEIN, Airton Roberto et al. Revisão tarifária do transporte rodoviário intermunicipal de passageiros da aglomeração urbana do sul. In: CONGRESSO BRASILEIRO DE REGULAÇÃO, VI, 2009, Rio de Janeiro. Anais eletrônicos... Disponível em: $<$ http://www.workoutenergy.com.br/abar/c br/Trab0904.pdf >. Acesso em: 11 jun. 2015.

RIO GRANDE DO SUL. Lei

Complementar N. 11.876, de 26 de dezembro de 2002. Altera disposições da Lei Complementar n ${ }^{\circ} 9.184$, de 26 de dezembro de 1990, revoga a Lei Complementar $\mathrm{n}^{\circ} 10.816$, de 15 de julho de 1996, transforma a Aglomeração Urbana de Pelotas em Aglomeração Urbana do Sul, agregando novos Municípios a esta, e dá outras providências. Porto Alegre, 2002. Disponível em:

<http://www.al.rs.gov.br/legis/M010/M010 0099.ASP?Hid_Tipo=TEXTO\&Hid_Toda sNormas $=2920 \& h$ Texto $=\& H i d \_I D N o r m a$ $=2920>$. Acesso em: 10 jun. 2015 .

RIO GRANDE DO SUL. Lei Complementar N. 12.100, de 27 de maio de 2004. Institui a Aglomeração Urbana do Litoral Norte, dispõe sobre a gestão regional e dá outras providências. Porto Alegre, 2004. Disponível em: <http://www.al.rs.gov.br/legis/M010/M010 0099.ASP?Hid_Tipo=TEXTO\&Hid_Toda sNormas $=47628 \&$ hTexto $=\&$ Hid_IDNorma $=47628>$. Acesso em: 10 jun. 2015 . agosto de 2013. Cria a Região Metropolitana da Serra Gaúcha. Porto Alegre, 2013. Disponível em: <http://www.al.rs.gov.br/legis/M010/M010 0099.ASP?Hid_Tipo=TEXTO\&Hid_Toda sNormas $=59694 \&$ hTexto $=\&$ Hid_IDNorma $=59694>$. Acesso em: 10 jun. 2015 .

\section{RIO GRANDE DO SUL. Lei N.} 10.931/97, de 09 de janeiro de 1997. Cria a Agência Estadual de Regulação dos Serviços Públicos Delegados do Rio Grande do Sul - AGERGS e dá outras providências. Porto Alegre, 1997.

Disponível em: <http://www.al.rs.gov.br/FileRepository/re pLegisComp/Lei\%20n\%C2\%BA\%2010.93 1.pdf $>$. Acesso em: 10 jun. 2015.

SANTOS, Thiago de Oliveira; BRINCKMANN, Roque; CAMARGO, Raphael Vinicius Weigert. Análise comparativa dos Impactos da atual Contribuição Previdenciária sobre a Receita Bruta com a anterior Contribuição Previdenciária Patronal nas Empresas listadas na BM\&FBOVESPA, obrigadas ao seu Cálculo. In: Congresso UFSC de Controladoria e Finanças, 5., 2014, Florianópolis. Anais eletrônicos... Disponível em: $<$ http://dvl.ccn.ufsc.br/congresso/anais/5C CF/20140423150858.pdf>. Acesso em: 17 jun. 2015.

SOUSA, Felipe Brum de Brito.

Gerenciamento da qualidade no transporte coletivo de longa distância por ônibus. 2004, 171 f. Dissertação (Mestrado em Engenharia da Produção) Programa de Pós-Graduação em Engenharia de Produção, Universidade Federal do Rio Grande do Sul, Porto Alegre, 2004. 